\title{
EMOÇÕES CORPORIFICADAS: UMA PERSPECTIVA SISTÊMICA SOBRE ESTADOS EMOCIONAIS ${ }^{1}$
}

EMBODIED EMOTIONS: A SYSTEMIC PERSPECTIVE ON EMOTIONAL STATES

\author{
MATHEUS DE MESQUITA SILVEIRA ${ }^{2}$ \\ Universidade de Caxias do Sul (UCS) - Brasil \\ mdm.silveira@gmail.com
}

\begin{abstract}
RESUMO: A tese principal deste artigo é que emoções são parcialmente constituídas por estados corporais. No centro da discussão está a tradição James-Lange e serão estabelecidas duas premissas para identificar as abordagens mais relevantes acerca desse ponto: (i) a Premissa de James, que será investigada a partir do trabalho do próprio autor; e (ii) a Premissa de Lange, que será investigada a partir do trabalho de Prinz. Embora se inscreva na mesma tradição, a perspectiva apresentada neste artigo diverge de ambas posições ao defender uma visão sistêmica, na qual as emoções são constituídas tanto por estados periféricos corporificados quanto por estados cerebrais. A visão sistêmica parece vulnerável a duas críticas principais: (i) de que as emoções, ao contrário de estados corporais, possuem intencionalidade; e (ii) as neurociências mapearam as bases neurais das emoções, então não há motivo para colocar fora do cérebro os componentes que as constituem. Em relação à primeira crítica, argumenta-se que as emoções não possuem intencionalidade direta, uma vez que não influenciam os comportamentos de modo específico, como objetos ou conteúdos representacionais o fazem. No tocante à segunda crítica, as conclusões das neurociências dizem menos do que aparentam acerca dos constituintes das emoções. A confusão na literatura empírica resulta da falha em distinguir corretamente emoções de desejos. Isso será realizado mediante a análise do debate entre as teorias de James-Lange para, posteriormente, mostrar como a Premissa de Lange desconstrói teorias relevantes desta posição, inclusive a sua própria.
\end{abstract}

PALAVRAS-CHAVE: Emoções. Estados corporais. Estados cerebrais. James. Lange.

ABSTRACT: The main thesis of this article is that emotions are partly constituted by bodily states. The James-Lange tradition is key to this discussion, by considering emotions as bodily perceptions. In order to identify the most relevant general approaches to this subject, two premises will be established: (i) James' premise, which will be investigated from the author's work; and (ii) Lange's premise, which will be investigated from Prinz's work. Although the perspective presented in this article subscribes to the previously mentioned tradition, it diverges from both premises by the defense of a systemic view in which emotions are constituted by both embodied peripheral states and brain states. The systemic view seems vulnerable to two main critiques: (i) that emotions, unlike bodily states, have intentionality, and (ii) that neuroscience has mapped the neural basis of emotions, so there is no reason to place their constituent components outside the brain. Regarding the first criticism, it is argued that emotions do not have direct intentionality, since they do not influence the behaviors in the particular way that both objects and representational contents do. As for the second critique, neuroscience's conclusions show less than they seem to about the constituents of the emotions. The confusion in the empirical literature results from failure to correctly distinguish emotions from desires. This will be accomplished by analyzing the debate between James-Lange's theories, to present how Lange's premise undermines relevant theories of those positions, including his own.

KEYWORDS: Emotions. Bodily states. Brain states. James. Lange.

${ }^{1} \mathrm{O}$ presente artigo foi desenvolvido com apoio da FAPERGS/CAPES, a partir do edital 03/2018.

${ }^{2}$ Programa de Pós-Graduação em Filosofia da Universidade de Caxias do Sul (UCS). 


\section{INTRODUÇÃO}

O ponto central de discussão deste artigo se refere à possibilidade de estados emocionais serem reduzidos a percepções corporais. James (1922) foi um dos primeiros pesquisadores a sistematicamente considerar essa hipótese, defendendo que percepções desse tipo compõem a natureza única das emoções. Nesta investigação, essa posição será identificada como a Premissa de James. Caso essa hipótese seja aceita, então é preciso considerar que os estados emocionais consistem nas expressões associadas a uma ou mais emoções, ou seja, em percepções corporais. Essa posição será chamada de visão perceptiva. Todavia, caso essa hipótese seja negada, então é preciso investigar a possibilidade de compreender os estados emocionais por meio de outras posições teóricas.

Uma posição semelhante à Premissa de James foi defendida por Lange (1922). O autor defende que alterações no corpo influenciam as emoções, evidenciando-se pelo uso de substâncias psicoativas ou redução da ansiedade após um exercício matinal. Para o autor, a melhor explicação para tais efeitos é a de que as emoções são redutíveis a estados periféricos corporificados ${ }^{3}$. Nesse sentido, o argumento de que a alteração desses estados pode desencadear emoções será denominado Premissa de Lange e essa posição será chamada de visão periférica. A questão é que, caso os estados emocionais sejam mediados por percepções corporais, então essa posição poderá ser interpretada como afirmativa no que toca ao papel da causalidade dentro de uma fenomenologia das emoções.

A Premissa de Lange se contrapõe às posições que identificam intrinsecamente emoções com atitudes proposicionais, como a apresentada por muitas teorias cognitivistas e da apreciação ${ }^{4}$. A dificuldade dessas posições está em explicar por que variações específicas nos estados periféricos desencadeiam determinadas alterações emocionais. A vantagem da Premissa de James é que ela apresenta uma explicação consistente com a perspectiva naturalista. O autor afirma que uma fenomenologia das emoções está circunscrita por percepções corporais, as quais produzem as características fisiológicas inerentes aos estados emocionais. Entretanto, essa posição diverge da Premissa de Lange no que concerne à questão de as emoções terem como efeito as percepções corporais ou, pelo menos, serem idênticas a elas. Portanto, ambas as premissas apontam na direção de que apenas uma está correta; a questão é como resolver o problema. Desse modo, um ponto importante discutido neste artigo é o de que a Premissa de Lange desconstrói teorias das emoções relevantes dentro desta tradição, incluindo a sua própria.

Neste artigo, será proposta uma nova perspectiva sobre as emoções, que parte da visão periférica e visa responder aos problemas identificados nesta posição teórica. O caminho parte de uma revisão de literatura da psicologia

\footnotetext{
${ }^{3}$ Considerando que o cérebro é uma estrutura corporal, na discussão acerca da corporificação para além do cérebro será utilizado o termo estado periférico, no lugar de corpo ou estado corporal. Da mesma forma, será utilizado o termo percepção corporal para se referir às percepções dos próprios estados periféricos do sujeito.

${ }^{4}$ Embora não seja objeto de discussão deste artigo, o leitor que desejar maior aprofundamento neste ponto poderá verificar que Solomon (1988) e Nussbaum (2001) são comumente colocados como cognitivistas, enquanto Ellsworth e Scherer (2003) estão identificados com uma teoria da apreciação.
} 
cognitiva social e das neurociências que embasam a Premissa de Lange, de modo a usar as mesmas bases empíricas das críticas mais proeminentes à tradição JamesLange. Isso será realizado a partir da discussão da teoria desenvolvida por Prinz (2004), antes de recorrer ao próprio trabalho de Lange (1922). Na parte final deste artigo será apresentada uma variação da visão periférica, que receberá o nome de visão sistêmica, argumentando-se que é a teoria mais adequada para explicar a Premissa de Lange do que outras dessa tradição.

\section{Premissa De Lange a a literatura empírica das emoções}

As evidências apresentadas por Lange (1922), que defende a possibilidade de alterar ou incitar emoções mediante a manipulação de estados periféricos, estão embasadas majoritariamente em observações pessoais. Contudo, há um campo diversificado de pesquisas empíricas que reforçam sua posição. Nesta seção serão examinadas evidências dessa natureza, de modo que seja possível discutir posteriormente suas implicações às teorias das emoções apresentadas neste artigo.

O primeiro ponto desta parte será demonstrar que alterações no estado periférico incitam emoções. A análise das expressões faciais tem sido a metodologia mais utilizada em pesquisas sobre manipulação periférica. Essa perspectiva foi desenvolvida inicialmente por Darwin (1872), ao sustentar que as alterações fisiológicas causadas pelas emoções geram um impacto direto nelas, ao invés de simplesmente serem uma consequência. Em linhas gerais, a ideia é que os movimentos faciais podem influenciar os estados emocionais.

A expressão livre mediante sinais externos de uma emoção a intensifica. Por outro lado, a repressão, tanto quanto possível, de todos os sinais externos suaviza nossas emoções [...] Até mesmo a simulação de uma emoção tende a despertá-la em nossas mentes (DARWIN, 1872, p. 366) 5 .

Strack et al. (1988) realizaram um experimento, no qual manipularam as expressões faciais dos participantes enquanto eles ouviam histórias, ao solicitar que segurassem um lápis na boca, de modo a forçar a expressão de um sorriso ou uma carranca. O resultado foi que, sem saber que manifestavam tais expressões, julgaram como mais divertidas as histórias quando o lápis os forçava a sorrir. Com a intenção de replicar os resultados do experimento acima, Soussignan (2002, p. 70) coloca que "um efeito congruente entre o Sorriso de Duchenne ${ }^{6}$ e os eventos que provocam emoções foi claramente apoiado pela autorreferência da experiência emocional e, parcialmente, pela reatividade do sistema nervoso autônomo". Em outras palavras, descobriu-se que apenas esse sorriso específico desencadeou uma emoção.

Evidências empíricas também são encontradas em pesquisas com diferentes abordagens sobre os estados periféricos. Stepper e Strack (1993) demonstraram

\footnotetext{
5 Todas as traduções no decorrer do texto são do autor.

${ }^{6}$ O Sorriso de Duchenne envolve a contração do músculo zigomático principal e do músculo orbicular dos olhos. Esse sorriso pode ser metaforicamente descrito como um sorrir com os olhos.
} 
que a postura corporal exerce influência na manifestação do orgulho, enquanto Philippot et al. (2002) identificaram padrões de respiração distintos relacionados a alegria, raiva, medo e tristeza. Os pesquisadores demonstraram que a indução de processos respiratórios é suficiente para incitar as respostas emocionais correspondentes. Esse é o mais intuitivo dos resultados apresentados até o momento, uma vez que diversas áreas da psicologia recomendam com solidez a utilização de padrões respiratórios para lidar com estados emocionais específicos.

As neurociências também fornecem evidências acerca dos estados periféricos. Adolphs et al. (2000) relatam que danos no córtex somatossensorial, diretamente associado à percepção corporal, prejudicam o reconhecimento visual de diversas expressões emocionais. Segundo Berntson et al. (2011), lesões na ínsula podem acarretar uma menor excitação e reação emocional como resposta a diferentes estímulos. Nessa linha, Craig (2009) coloca que a ínsula é ativada durante experiências emocionais e está diretamente conectada com os sistemas cerebrais associados à motivação.

\begin{abstract}
A amígdala pode não ser necessária para determinar se e em que medida um estímulo é desejável ou aversivo, hostil ou acolhedor; em vez disso, pode ser importante para registrar a excitação ou o impacto emocional de um estímulo (e especialmente dos estímulos aversivos). Em contraste, o córtex insular parece estar mais amplamente envolvido no reconhecimento, processamento e atribuição de valência avaliativa, e pode contribuir à excitação afetiva (BERNTSON et al., 2011, p. 85).
\end{abstract}

Tomadas sob uma perspectiva ampla, essas evidências suportam duas possíveis conclusões. A primeira conclusão é que as análises acerca da influência das expressões faciais e posturas corporais nas emoções, combinadas com as descobertas sobre o papel da ínsula e do córtex insular nos estados emocionais, apontam que os estados periféricos produzem efeitos motivacionais inerentemente emocionais. A segunda conclusão consiste no fato de que tanto as pesquisas sobre as funções da ínsula e do córtex insular quanto as do córtex somatossensorial conferem plausibilidade à posição de que os estados periféricos desempenham um papel central na autoconsciência das próprias emoções.

A literatura empírica não apenas reforça a Premissa de Lange como abre espaço para que uma perspectiva corporificada seja central a essa posição. De fato, a visão periférica permite que se considere que as emoções consistam em alterações padronizadas no corpo, porém enraizadas em sistemas cerebrais evolutivamente ancestrais e compartilhados por inúmeras espécies. Sendo assim, evidências empíricas que atestem uma relação entre alterações fisiológicas e emoções não apenas contribuirão na defesa de uma perspectiva evolucionista à questão como também reforçarão o argumento naturalista sobre o papel das emoções enquanto motivadoras de comportamento. A posição de que estados periféricos produzem efeitos motivacionais com base nas emoções está direcionada à confirmação da Premissa de Lange. Já a perspectiva de que os sistemas cerebrais possibilitam que os estados periféricos sejam centrais à autoconsciência emocional 
consiste na pedra de toque à avaliação da especificidade periférica. Esse segundo ponto será o foco de investigação da próxima seção deste artigo.

\section{EMOÇÕES E ESPECIFICIDADES PERIFÉRICAS}

Um problema empírico importante, enfrentado tanto por teorias da percepção corporal como dos estados periféricos, pode ser denominado de especificidade periférica. A questão colocada é que, caso emoções sejam corporificadas, então na visão periférica cada uma estaria correlacionada com um tipo diferente de estado periférico. A visão perceptiva também requer essa correlação pois, caso contrário, as percepções dos estados periféricos não seriam distintas entre si. Em ambas as visões, é necessário que ocorra uma variação suficiente entre os estados periféricos relevantes para que seja possível explicar variações entre as emoções.

O primeiro passo para responder esse problema é esclarecer como as emoções podem ser individualizadas. A visão periférica afirma que toda emoção é um tipo específico de estado periférico. No entanto, a pergunta é se esse posicionamento realmente está comprometido com a visão de que todo estado periférico consiste em um tipo de emoção. Essa relação é necessária, pois de outro modo não seria possível distinguir emoções de outros tipos de estados periféricos. O ponto é que a visão periférica precisa considerar todas as emoções associadas às percepções corporais, pois, caso não o faça, seria impossível distingui-las de outras formas de percepções desta natureza.

Acredita-se que a melhor forma de abordar essa questão é a partir da funcionalidade das emoções. As abordagens dentro da linha teórica estabelecida por James-Lange que não relacionam as emoções com estados cognitivos representativos de relações com o meio externo como, por exemplo, o perigo ou a perda, foram definidas por Smith e Lazarus (1990) como ancoradas em temas relacionais centrais. Todavia, as teorias corporificadas poderiam sustentar que a funcionalidade das emoções consiste no auxílio para lidar efetivamente com as circunstâncias externas ao sujeito. Portanto, elas seriam despertadas exatamente pelos estados corporais e módulos cerebrais cuja função é detectar situações deste tipo.

A tarefa da apreciação para a pessoa é avaliar as circunstâncias percebidas em termos de um número relativamente pequeno de categorias de significância adaptativa, correspondendo a diferentes tipos de benefício ou dano, cada um com diferentes implicações para o enfrentamento. Uma proposição chave de uma teoria cognitivo-relacional da emoção é que o processo de avaliação resulta na identificação de uma relação de pessoa-ambiente molar, ou o que chamamos de "tema relacional nuclear", e que cada tema distinto resulta numa emoção distinta (SMITH e LAZARUS, 1990, p. 617).

De modo a realizar uma possível distinção entre emoções e estados periféricos, é necessário apenas determinar se um estado periférico específico é 
despertado como resposta a uma circunstância particular. Somente em caso afirmativo é que poderia ser caracterizado como emocional. O problema é que tanto as percepções corporais quanto os estados periféricos como, por exemplo, a sede, não podem ser simplesmente definidos como emoções. No caso citado, sua funcionalidade está associada ao equilíbrio interno do organismo mediante a hidratação, e não à prestação de auxílio relativo a alguma condição externa.

A partir do exposto acima, considera-se necessário que teorias corporificadas relacionem determinadas emoções com manifestações específicas de estados periféricos. O problema está caso existam dois estados periféricos para uma mesma emoção e vice-versa. Entretanto, sustenta-se que uma incompatibilidade não é motivo suficiente para abandonar toda a abordagem, uma vez que o ponto problemático pode simplesmente estar na forma pela qual se está individualizando as emoções. Por exemplo, caso o ciúme e a raiva possuam os mesmos estados periféricos, pode-se propor que não exista uma diferença intrínseca entre ambas as emoções. Da mesma forma, o medo pode estar relacionado a dois estados periféricos diferentes, sendo plausível a proposta de que ele simplesmente seja manifestado por mais de uma expressão. Para realizar essas classificações, seria necessário um método mais preciso sobre como individuar as emoções e os estados periféricos. A questão é que as abordagens advindas exclusivamente da literatura conceitual são contraditórias e não apresentam uma solução clara para esse ponto.

Considerando as incongruências que permeiam a discussão estritamente conceitual deste problema, dados empíricos tornam-se interessantes guias de investigação. Os estados periféricos mencionados pelas teorias corporificadas das emoções são controlados pelo sistema nervoso periférico, que é dividido entre os sistemas nervosos autônomo e somático. Esse último é responsável pelos músculos passíveis de serem controlados voluntariamente, como os associados a expressões faciais, vocalizações, níveis de tensão muscular e movimentos corporais coordenados, ou seja, todos os que apresentam variação na manifestação de emoções. Por sua vez, o sistema nervoso autônomo controla a forma e a intensidade da excitação corporal.

Kreibig (2010, p. 394) relata uma "considerável especificidade de resposta do sistema nervoso autônomo na emoção ao considerar subtipos de emoções distintas". De fato, a autora salienta que um estado de excitação emocional aumentará em correlação com a frequência cardíaca, a transpiração e o fluxo sanguíneo em diferentes partes do corpo. Segundo Folkow (2000), as alterações simpáticas tendem a aumentar o grau de excitabilidade, enquanto as parassimpáticas o diminuem. Em outras palavras, mudanças fisiológicas viscerais estão associadas com emoções.

[...] cada órgão e tecido é inervado por vias simpáticas e parassimpáticas distintas, sugerindo que cada órgão e tecido tem alguma independência funcional [...] Considera-se que esta independência pertence ao sistema medular simpático-adrenal, para o qual há uma influência direta do sistema nervoso, e uma influência de hormônios adrenomedulares que, na maioria das 
situações, têm diferentes papeis funcionais (STORBECK e WYLIE, 2018, p. 202).

Argumenta-se que não há necessidade das teorias dentro da linha de JamesLange demonstrarem a existência de uma especificidade autonômica ou somática. Considerando como é formado o sistema nervoso periférico, de fato há menor gasto energético se duas ou mais emoções estiverem correlacionadas ao mesmo estado autonômico, desde que também o estejam com relação a diferentes estados somáticos e vice-versa. Contudo, pesquisas sobre a especificidade periférica têm metodologicamente se concentrado em analisar ambos os estados separadamente, motivo pelo qual o mesmo será realizado neste artigo.

Em defesa da especificidade somática, Ekman e Friesen (1971) argumentam que existem expressões faciais universais intrínsecas às emoções básicas. Em sua pesquisa, os autores apresentam que mesmo os participantes que não possuíam contato com a cultura ocidental associavam expressões faciais específicas as mesmas emoções. Dessa perspectiva decorre a defesa de que as emoções básicas de medo, raiva, tristeza, nojo, surpresa e alegria estão associadas a expressões universalmente correspondentes e independem de fatores socioculturais.

A experiência dentro de uma cultura, os tipos de eventos que tipicamente provocam emoções particulares, podem influenciar a capacidade de discriminar pares específicos de emoções. Os rostos de medo podem não terem sido distinguidos dos rostos de surpresa, porque nessa cultura os eventos de medo também são quase sempre surpreendentes; isto é, o súbito aparecimento de um membro hostil de outra aldeia, o encontro inesperado de um fantasma ou feiticeiro, etc (EKMAN e FRIESEN, 1971, p. 129).

A crítica que pode ser feita é que os resultados apresentados acima se devem a uma escolha de paradigma forçada, na qual é conferido aos participantes um conjunto limitado de emoções para escolher. Russell (1994, p. 116) coloca que "não foi dada aos participantes a opção de dizer nenhuma das alternativas acima [...] Eles não tinham autorização para descrever o rosto com parte de uma resposta instrumental [...]". O autor apresenta que os resultados encontrados mediante metodologias de livre escolha são mais variados. No entanto, mesmo em métodos de escolha forçada, é relevante o dado associado à invariabilidade cultural entre expressões faciais e emoções.

Expressões faciais podem estar inter-relacionadas com alterações somáticas e autonômicas, o que possibilitaria a distinção coletiva de diferentes emoções. Prinz (2004) enfatiza que percepções corporais não necessitam que mudanças nos estados somáticos estejam perfeitamente correlacionadas com emoções específicas. Em geral, as teorias corporificadas não sustentam a necessidade de emoções serem exclusivamente inatas. Entende-se que o seu fundamento biológico não é reducionista, uma vez que a cultura pode influenciar parcialmente as emoções, que são biologicamente aptas a receber estes estímulos.

É possível que as características que compõem as expressões faciais sejam desencadeadas por sistemas de resposta inatos, enquanto 
todo o conjunto depende do fato de que as condições que provocam estas respostas muitas vezes ocorrem conjuntamente (PRINZ, 2004, p. 88).

Pesquisas sobre alterações de estados autonômicos associados à frequência cardíaca, à pressão arterial e à resposta galvânica de pele também são relevantes em pesquisas sobre emoções. Ekman et al. (1983) demonstram que determinadas mudanças autonômicas são correlatas às emoções específicas. Todavia, Cacioppo et al. (2000) ressaltam que essa correlação é distinguível apenas no tocante a grupos de emoções. A raiva, o medo e a tristeza apresentam maior alteração na frequência cardíaca e menor atividade vascular que o nojo, da mesma forma que este apresenta maior resposta galvânica de pele que a alegria. Ainda que os resultados empíricos não sejam uniformes, Sequeira et al. (2009) salientam que grande parte dos dados reforçam a hipótese de que emoções possuem assinaturas autonômicas distintas.

A crítica a uma abordagem corporificada das emoções pode ser realizada salientando o vasto número de pesquisas com resultados inconclusivos ou disformes entre si. Por sua vez, a defesa pode ressaltar que há dificuldades metodológicas advindas de limitações tecnológicas para realizar uma quantificação empírica e, mesmo assim, há dados que apontam a existência de correlações entre emoções e estados periféricos. O desenvolvimento de melhores métodos de individuação e maior precisão indutiva acerca das emoções certamente trarão uma nova luz à questão. Entretanto, neste momento não é possível tirar conclusões empíricas fortes acerca da especificidade periférica. Dessa forma, será defendida neste artigo uma abordagem corporificada com base em outros alicerces, que serão apresentados na próxima seção.

\subsection{EMOÇÕES E ESTÍMULOS PERIFÉRICOS}

Pesquisas sobre os efeitos de lesões na medula espinhal sobre emoções conferem uma nuance interessante à discussão sobre emoções corporificadas. Cannon (1927) defende que pacientes nessas condições não apresentam alterações nas suas capacidades de sentir emoções. Como resposta, abre-se a possibilidade de as emoções serem apenas percepções corporais. Hohmann (1966, p. 149) defende que a emoção "é um tipo de pensamento mental em vez de uma sensação dirigida fisicamente”. Contudo, o próprio autor ressalta que lesões medulares mitigam as emoções, ainda que não as eliminem.

Elas podem ser controladas, no entanto, pelos processos no córtex cerebral, por processos condicionados por todos os tipos de impressões anteriores. O córtex também pode controlar toda a maquinaria periférica, exceto as vísceras. Os processos inibitórios no tálamo não podem colocar o organismo em ação, exceto as partes que não estão sob controle voluntário, mas a agitação lá pode produzir emoções da maneira usual, e possivelmente com maior violência por causa da inibição (CANNON, 1927, p. 123). 
Chwalisz et al. (1988) analisaram pacientes com lesão na coluna vertebral e relataram que eles apresentaram emoções intensas. No que toca ao medo, os autores demonstram que a pontuação dos pesquisados com relação ao grupo de controle foi maior. Essa divergência pode ocorrer caso os participantes do experimento de Hohmann (1966) tenham oferecido relatos imprecisos acerca do que estavam sentindo. Em uma perspectiva histórica, práticas terapêuticas encorajaram a adoção de posturas estoicas com relação a lesões desse tipo, o que pode resultar em um efeito de contraste nas pesquisas. Afinal, o trauma da lesão pode ser tão intenso que outras emoções são mitigadas por comparação. As próprias condições de sobrevida do período impediam esses pacientes de possuir qualidade de vida, levando-os a um ostracismo emocional. A mudança nessa perspectiva pode explicar o porquê de pacientes nessas condições terem apresentado maior intensidade em suas experiências emocionais. O ponto é que nenhuma das pesquisas apresentadas refutam categoricamente perspectivas somáticas das emoções.

Não há concordância dentro da literatura empírica sobre essa questão, o que torna relevante averiguar se há pontos de convergência nas pesquisas sobre o tema. A pesquisa de Heims et al. (2004) teve como foco pacientes com falha autonômica em vez de lesão na medula espinhal. Os autores descobriram que eles participavam normalmente do Iowa Gambling Task ${ }^{7}$, mas falhavam ao atribuir emoções a personagens de histórias curtas. Não houve alteração nas respostas somáticas dos participantes, ainda que apresentassem deficiências autonômicas. $\mathrm{Na}$ verdade, isso explica o porquê de suas reações não serem particularmente intensas. A questão é que a evidência empírica de que uma falha autonômica dificulta a atribuição de emoções oferece suporte à visão perceptiva e à visão periférica. No escopo das teorias tradicionais sobre as emoções, torna-se difícil compreender o motivo de uma deficiência autonômica interferir em uma emulação empática efetiva.

Não ocorreu interação do grupo com a emoção [...]. No entanto, a ANOVA revelou um efeito maior no grupo [...] com pacientes de performance pior que o grupo de comparação. O desempenho fraco dos pacientes nessa tarefa sugere que repostas autônomas corporais podem ter um papel na previsão, talvez por emulação empática, dos estados de sensibilidade emocional subjetivos de outros (HEIMS et al., 2004, p. 1984).

O problema consiste em explicar o motivo pelo qual emoções não são extinguidas por lesões da medula espinhal. Quanto a isso, Prinz (2004) atenta para

\footnotetext{
${ }^{7}$ O Iowa Gambling Task é um teste psicológico pensado para simular tomadas de decisões da vida real. Foi introduzido inicialmente por Bechara et al. (1994) e ganhou notoriedade quando Damásio (1994) propôs a hipótese dos marcadores somáticos. De fato, o autor defende que as emoções usam o corpo como seu teatro e afetam o modo como vários circuitos cerebrais operam. Nesse sentido, a variedade das respostas emocionais exerce um papel causal nas mudanças tanto nos estados corporais quanto nos cerebrais. Para Damásio (1999), o conjunto destas mudanças subsidiam os padrões neurais que se tornam a sensação consciente da emoção. Embora não seja o escopo deste artigo, com relação ao caso apresentado no texto, sugere-se que o desempenho dos sujeitos não se deve a questões emocionais, mas a desejos deficientes. Nesse sentido, uma deficiência emocional não influenciaria, necessariamente, o desempenho no teste.
} 
a possibilidade de haver estímulos periféricos no rosto ou em outras partes do corpo não afetados por lesões desse tipo. Essa posição torna possível a uma abordagem corporificada explicar a experiência emocional relatada por pacientes com essa debilidade, pois a diferença é que seria estimulada por um escopo mais estreito dos estados periféricos.

\begin{abstract}
Evidências da indução corporal da emoção, lesão da medula espinhal e neuroimagem sugerem que emoções são a consequência causal de mudanças corporais. Elas são estados que registram mudanças corporais. Caso este seja o caso, então mudanças corporais devem ser capazes de causar emoções. Isto não significa que toda emoção é o resultado de alguma perturbação anterior no corpo, mas sugere que as perturbações são causas confiáveis das emoções (PRINZ, 2004, p. 58).
\end{abstract}

Outra possibilidade é que as emoções poderiam resultar de uma alucinação relativa aos estados periféricos. Na visão perceptiva, isso significa a possibilidade de emoções reais resultarem de percepções alucinatórias. A visão periférica, ao contrário, teria que defender a inexistência de qualquer emoção real, pois do delírio dos estados periféricos decorreria necessariamente a alucinação emocional.

A literatura empírica sobre a relação entre estímulos periféricos e lesões corporais está longe de ser conclusiva. A posição que encontra maior convergência é a de que há alguma interferência no funcionamento das emoções, sempre que os estados periféricos forem incapazes de enviar estímulos ao cérebro. Até o momento, a perspectiva na qual toda emoção depende desses estímulos não é corroborada nem refutada. Uma vez que as evidências empíricas são incapazes de falsear as perspectivas corporificadas, essa posição teórica é reforçada. Na pendência de evidências ou melhores argumentos de refutação, a questão a ser abordada passa a ser o modo como as emoções podem ser influenciadas por estímulos periféricos.

\title{
3 EMOÇÕES E CONIEÚDO REPRESENTACIONAL
}

No escopo da abordagem de James-Lange, grande parte das teorias estão próximas da visão perceptiva. Isso ocorre por elas considerarem que alterações periféricas resultam de diferentes emoções. A questão levantada nesta seção é se elas são capazes de explicar como e por que ocorrem essas mudanças. Dada sua correlação e aprimoramento da visão perceptiva, a teoria de Prinz (2004) será tomada como representativa da Premissa de James.

Contemporaneamente, a visão perceptiva ganhou contornos psicossemânticos. Prinz (2004, p. 190) coloca que "emoções envolvem estados corporais, mas não representam estados corporais. Elas usam estados corporais para representar as relações organismo-ambiente”. O autor defende que um módulo de calibração consiste em um grupo de sistemas cerebrais cuja função é causar as alterações periféricas idênticas às relacionadas com determinada emoção. O medo de baratas é um bom exemplo para explicar esse ponto. A percepção do inseto ou de seus rastros faz com que se conclua que ele está próximo. A 
percepção da barata seria uma crença de existência cujo conteúdo é há uma barata por perto. Toda vez que o inseto estiver presente, ou a sua lembrança, a percepção correspondente registrada no módulo de calibração desencadeará um estado periférico associado ao medo.

A reação apresentada acima não corresponde ao medo, mas a uma percepção associada a um estado periférico. A visão perceptiva possui um aspecto contraintuitivo, uma vez que o medo tem na barata a sua referência, e não a aceleração da frequência cardíaca ou qualquer outra alteração periférica. O problema é como equalizar o medo como uma percepção corporal, e a resposta está em uma teoria causal do conteúdo representacional.

Nesta abordagem, um estado carrega informação sobre aquilo com
o que ele ocorre simultaneamente de forma confiável. Nos casos
mais típicos, a ocorrência simultânea em questão é causal. Um
estado carrega informações sobre o que faz com que ele ocorra de
maneira confiável. A causação confiável não implica correlação
perfeita. Dizer que uma coisa é causada de forma confiável por
outra coisa significa apenas que, caso aquela segunda coisa
ocorresse, então, todas as coisas sendo iguais, a primeira teria uma
alta probabilidade de ocorrer como resultado (PRINZ, 2004, p. 53).

O conteúdo representacional de um objeto surge mediante a apreensão de informações sobre suas características. Sempre que o conteúdo apreendido representa propriedades do objeto, então elas podem ser consideradas como o conteúdo nominal da representação. Diferentemente, o conteúdo real consiste nas características essenciais da classificação natural dentro da qual determinado objeto se encontra. No momento em que o conteúdo representacional é composto de informações apreendidas diretamente do conteúdo real, então essas características consistem no conteúdo real da representação.

O conteúdo nominal de uma representação corresponde a alterações pontuais nos estados corporais. Por exemplo, o medo decorre da percepção de se encontrar em um estado periférico específico. O conteúdo real desta percepção pode ser expresso como estou em perigo. A literatura dentro da visão perceptiva coloca essa relação como um tema relacional nuclear. Lazarus (1991, p. 121) define que "um tema relacional nuclear é simplesmente o dano ou benefício central (consequentemente nuclear) em encontros adaptativos que subjazem cada tipo específico de emoção". Há inúmeras relações benéficas e cada uma delas constitui um tema relacional nuclear que desencadeia uma emoção positiva distinta, como a alegria associada à conquista de um objetivo. A abordagem defendida por Prinz (2004) consiste exatamente na defesa de que o conteúdo das emoções são os temas relacionais centrais.

A ideia é que o conteúdo representacional possa rastrear os conteúdos reais tendo como ponte conteúdos nominais, mas isso levanta um problema acerca das emoções. No momento em que elas não detectam necessariamente um tema relacional nuclear mediante a sua descrição, então também não poderiam detectar sua essência. Todavia, disso não decorre que as emoções estejam ausentes de estrutura ou que consistam em meros indicadores. A resposta a essa questão passa 
por uma aproximação entre uma teoria da apreciação e a visão perceptiva. Em linhas gerais, as emoções rastreariam temas relacionais nucleares a partir do registro de alterações nos estados corporais.

A visão perceptiva coloca como possível que qualquer propriedade essencial de um animal possa ser classificada como o conteúdo representacional associado a ele. Prinz (2002, p. 149) exemplifica que se "alguém está procurando por cães na tundra ártica, alguém pode invocar a representação de um típico cão de trenó". Nesse caso, as características desses animais consistem apenas no conteúdo nominal do conceito humano associado a cães de trenó. Para o autor, a referência ao conteúdo real ocorre a partir do registro dos conteúdos representacionais e nominais, com os sistemas cerebrais presentes nos módulos de calibração separando os dois últimos. Prinz (2004, p. 68) destaca que "os detectores de rastreamento de essência têm conteúdo real e conteúdo nominal, mas com os detectores de rastreamento de aparência, estes se separam". Dessa forma, o conteúdo representacional de cães de trenó está vinculado aos estímulos periféricos reais causados por esses animais.

O argumento tem como premissa que emoções são percepções corporais, o que parece contraditório com a alegação de que elas consistem em temas relacionais nucleares. A tentativa de distensionar ambas as posições se dá pela defesa de que emoções representam temas relacionais nucleares a partir da percepção de alterações corporais. Por exemplo, o medo rastreia o perigo através de palpitações cardíacas da mesma forma que o conceito de cão de trenó o faz por meio das características físicas desses animais. Dessa forma, os temas relacionais nucleares são o conteúdo real das emoções, enquanto as alterações corporais consistem no seu conteúdo nominal.

\begin{abstract}
A evolução, sem dúvida, nos dotou com respostas fisiológicas distintas para várias situações que nossos ancestrais encontraram. O coração está predisposto a acelerar (junto com diversas outras respostas fisiológicas) quando percebemos objetos iminentes, cobras, insetos rastejantes, ou sombras grandes se movendo na noite; ou quando ouvimos sons altos ou gritos específicos; ou quando sentimos o cheiro de um predador. O coração acelerado e outras alterações fisiológicas que ocorrem coletivamente nestas condições servem como um detector de perigo (PRINZ, 2004, p.
\end{abstract} 69).

A correlação entre temas relacionais nucleares e percepções corporais é possível devido ao modo como fora estabelecida sua conexão. Percepções corporais de perigo evoluíram de modo a engatilhar as mudanças fisiológicas apropriadas, sendo que esta conexão pode ser tanto genotípica quanto fenotípica. Independentemente de sua matriz, repostas ao perigo estão baseadas em um sistema filogenético primitivo que predispõe determinadas reações com relação a eventos dessa natureza.

O conteúdo das emoções consiste em temas relacionais nucleares, cabendo ao estado periférico informar a sua existência. Nos módulos de calibração estão contidas informações sobre temas relacionais nucleares específicos, que causam a 
ocorrência de percepções corporais através de sistemas cerebrais. Emoções consistem nessas percepções corporificadas na medida em que elas representam determinado tema relacional nuclear mediante a modificação de um estado periférico. Nesse sentido, uma emoção é uma reação visceral. Considerando que temas relacionais nucleares aparentemente seriam de importância vital para a sobrevivência, a funcionalidade das emoções seria tornar consciente a sua existência.

\subsection{EMOÇÕES E PERCEPÇÕES CORPORAIS}

A relação entre a visão perceptiva e os temas relacionais nucleares pode ser criticada por descaracterizar o papel das percepções corporais. Uma forma de compreender esse ponto é a partir do exemplo de alguém que sente um aperto no peito e fraqueza nas pernas ao saber que perdeu o emprego. Essas reações não necessitam da consciência acerca das dificuldades futuras para serem sentidas. A percepção do estado periférico é posterior às alterações corporais, pois ela simplesmente torna consciente o estado de ansiedade ou medo existente. Essa crítica é plausível, uma vez que a própria tentativa de evitar a expressão dessas emoções requer esforço e possui um alto custo energético. Ao contrário da teoria apresentada na seção anterior, no exemplo acima as percepções corporais não tornam conscientes os temas relacionais nucleares, mas as próprias emoções.

No entanto, a capacidade de percepções corporais tornarem conscientes temas relacionais nucleares não pode ser descartada apenas pelo argumento do parágrafo anterior. Essas associações estão presentes na cultura popular, como no caso de um arrepio na nuca significar uma situação de perigo. Ainda que tenham algum grau de confiabilidade, é preciso uma relação mais forte do que esses relatos para inferir um tema relacional nuclear com base em uma determinada emoção. Acerca das emoções, Prinz (2004, p. 66) diz que "[...] elas são causadas de forma confiável por propriedades relacionais que pertencem ao bem-estar. Mas a representação requer mais do que a causação confiável”. Fisiologicamente, a piloereção é um correlato periférico do medo e os sistemas cerebrais que provocam essa reação têm a função de tornar consciente uma situação perigosa. A crítica é que se está inferindo o acesso a temas relacionais nucleares baseados em emoções a partir de crenças relacionais, o que não confere qualquer objetividade natural à relação.

Uma possível resposta a essa crítica é que ela não faz qualquer menção a uma abordagem psicossemântica. Afinal, sempre que a piloereção traz à consciência o perigo, a percepção corporal também o faz. Entretanto, tornar consciente determinada situação é insuficiente e Prinz (2004) é claro na defesa de que conteúdos representacionais estão vinculados a apreensão de informações. Uma vez que essa funcionalidade deriva de uma história evolutiva, torna-se menos plausível que temas relacionais nucleares sejam acessados diretamente.

É suficiente dizer que uma representação mental é um estado mental que é confiavelmente causado por algo e foi estabelecido evolutivamente ou por aprendizado para detectar esta coisa. 
Colocando mais concisamente, uma representação mental é um estado mental que foi criado para ser desencadeado por algo (PRINZ, 2004, p. 54).

O argumento é o de que conteúdos representacionais são estabelecidos de diferentes formas. Eles podem resultar do aprendizado, como no conceito de cão de trenó; ou do processo evolutivo, como em sistemas cujas células respondem à presença de perigo. Dretske (1988, p. 107) argumenta que eles "exibem as propriedades essenciais de crenças genuínas: eles têm um conteúdo proposicional, e sua posse desse conteúdo auxilia a explicar por que o sistema em que eles ocorrem se comporta da maneira como o faz". Nesse caso, os conteúdos representacionais poderiam ser engatilhados por situações diferentes das associadas à sua função original. Por exemplo, a capacidade de visualizar rachaduras finas em uma escada resulta de uma adaptação evolutiva relacionada a evitar quedas em precipícios. Burge (1986, p. 26) defende que "estas representações (percepções) são formadas por processos que são relativamente imunes à correção de outras fontes de informação; e as representações da visão inicial parecem ser totalmente independentes da linguagem". O módulo mental para detectar defeitos em superfícies permanece inalterado, mas sua gama de aplicação pode ser expandida.

É possível que os modelos representacionais se apliquem de maneira diferente, sem que as reações físicas ou os poderes discriminatórios sejam diferentes. Estes fatos, junto com o fato de que muitos eventos e estados mentais fundamentais são individualizados em termos dos modelos representacionais relevantes, são suficientes para gerar a conclusão de que muitos eventos e estados mentais não são individualisticamente individualizados: eles podem variar enquanto o corpo e os poderes discriminatórios da pessoa são concebidos como constantes (BURGE, 1986, p. 27).

A crítica ao argumento apresentado acima é que ele não oferece uma fundamentação sólida que fortaleça a hipótese de que representações corporais têm como função representar temas relacionais nucleares. Millikan (1993, p.11) coloca que "quando funciona adequadamente, uma representação mental ocorre simultaneamente com o que está representado, retrata o que se representa, e... participa em inferências apropriadas". Os módulos cerebrais desempenham esse papel em condições normais e estão ancorados em sistemas do cérebro herdados evolutivamente. Nessa perspectiva, a funcionalidade das percepções corporais é apenas trazer à consciência emoções que surgem como resposta a contextos situacionais contemporâneos. Em uma perspectiva psicossemântica, essa relação se encontra em uma corporificação das emoções, e não em temas relacionais nucleares.

Retratar, indicar e inferir estão igualmente envolvidos na representação humana, mas como normas biológicas e não como meras disposições. Não são os fatos sobre como o sistema opera que o tornam um sistema representativo e determinam o que ele 
representa. Ao contrário, são os fatos sobre o que estaria fazendo se estivesse operando de acordo com as normas biológicas (MILLIKAN, 1993, p. 10).

Há um ponto de discórdia, pois enquanto algumas posições consideram um erro a ativação de módulos cerebrais por contextos situacionais diferentes dos originais, outras colocam que isso nada mais é do que um desvio de função que aumenta o seu valor adaptativo. Essa discussão levanta o problema acerca do porquê percepções corporais representam emoções. A primeira alternativa de resposta considera que os estados periféricos podem compor as emoções de modo parcial ou integral. Dessa forma, uma percepção corporal é equivalente a uma emoção. A segunda possibilidade de resposta coloca que estados periféricos são causados por emoções e, consequentemente, são distintos delas. Essa posição é compatível com as teorias cognitivistas convencionais, pois a manifestação de estados periféricos é uma característica das emoções.

\subsection{EMOÇ̃̃ES E FATORES DE VALÊNCIA}

A segunda crítica à visão perceptiva defende que reforços internos são qualificadores de valência emocional. Abordagens comportamentais tendem a colocar que reforços são estímulos externos, definindo-os com relação à probabilidade de motivarem comportamentos futuros. Prinz (2004) defende esses reforços como internos, porém sem abandonar o viés comportamental, concordando que eles são definidos mediante seu impacto em ações vindouras. Essa perspectiva coloca que uma valência negativa está associada a um reforço interno negativo, da mesma forma que uma valência positiva está vinculada a um reforço interno positivo. Assim, a valência emocional pode ser vista como a expressão de maior ou menor negatividade ou positividade.

Identificar a valência com reforços internos explica por que as emoções às vezes impulsionam a aproximação ou o recuo. As emoções negativas nos encorajam a recuar das situações que as provocam, e emoções positivas nos encorajam a buscar as situações que as provocam (PRINZ, 2004, p. 174).

A distinção entre desejo e valência é que o primeiro representa um estado emocional associado com atos de fala imperativos, enquanto a segunda é um imperativo da ação. Por exemplo, o medo possui uma valência negativa, não apenas tornando consciente uma situação perigosa, mas motivando um comportamento de fuga. Prinz (2004, p. 174) sustenta que "[...] os RPIs [reforços positivos internos] e os RNIs [reforços negativos internos] servem como imperativos internos. Um RPI serve como um comando que diz algo como 'mais disso!', enquanto o RNI diz 'menos disso!'”. O autor defende que uma valência positiva ou negativa comporta a presença de um desejo da mesma polaridade. Em suma, a visão perceptiva coloca as emoções em duas polaridades; a percepção positiva de algo e o desejo que persista, e a percepção negativa de algo e o desejo que termine. 
A visão perceptiva sustenta que as emoções são percepções corporais dotadas de um fator de valência e, por isso, podem ser interpretadas como uma teoria sobre a valência das percepções corporais. Prinz (2004, p. 164) defende que a "[...] valência é uma característica real da nossa psicologia e é essencial à emotividade". Dessa forma, torna-se necessário que a valência emocional das percepções corporais motive a continuidade ou o encerramento de algo a partir de sua polaridade. A questão é que isso ocorre mesmo em casos não associados diretamente com emoções. A sensação da pressão dos dedos durante uma massagem possui valência positiva e estimula o desejo de que continue. A valência de percepções corporais tem a mesma funcionalidade para além das emoções, sendo que em nenhum caso perde o fator motivacional.

O problema consiste no fato de que a valência emocional deveria influenciar a resposta ao tema relacional nuclear. Smith e Kirby (2009, p. 104) reforçam essa relação ao sustentarem que "[...] cada emoção distinta tem seu próprio tema relacional nuclear distinto, o qual representa um tipo particular de relacionamento adaptativo às circunstâncias de alguém". Pode-se argumentar que as percepções corporais motivam a continuidade e a cessação de emoções e temas relacionais nucleares. A acrofobia é um exemplo, pois o sofrimento durante um episódio de medo intenso contém um fator motivacional suficiente para que se evite escalar montanhas. A valência negativa do medo está motivando a prevenção do perigo sob condições específicas, ou seja, evita-se o perigo para não sentir medo. A questão é que essa posição é mais consistente com a defesa de que a valência emocional estimula diretamente o desejo para prolongar ou encerrar emoções ao invés dos temas relacionais nucleares.

O resultado é que as emoções parecem conter duas partes distintas. Toda emoção tem uma valência, a qual compartilha com outras emoções. Porém, toda emoção também tem um perfil corporal distinto refletido por diferenças (às vezes sutis) na atividade neuronal (PRINZ, 2004, p. 163).

Caso a valência emocional não corresponda às percepções corporais, isso enfraquece a visão perceptiva. O problema é que, para que a valência emocional estimule o desejo pela continuidade ou encerramento de temas relacionais nucleares, é necessário que ela seja diferente das percepções corporais, pois estas o fazem com relação apenas às emoções. A crítica é que o argumento central da Premissa de James falha em sua tentativa de abarcar nuances importantes dessa questão.

Há grande plausibilidade na colocação de que o medo motiva o afastamento do perigo, enquanto a raiva leva ao seu confronto. Lerner e Keltner (2001) sustentam que a raiva motiva comportamentos de risco, da mesma forma que o medo eleva o grau de reticência diante de ações dessa natureza. O argumento é que essas emoções influenciam o comportamento em um escopo maior do que apenas o dos temas relacionais nucleares. Schnall et al. (2008) sustentam essa posição, defendendo que o nojo (emoção com valência negativa) confere maior severidade aos juízos morais. 
[...] os efeitos que encontramos do nojo nos juízos morais não são meramente a manifestação de uma tendência geral para que o afeto negativo amplifique os juízos morais. Assim, parece que quanto mais claramente os participantes estão sentindo nojo, mais diretamente esse afeto é tomado como atribuição para os juízos morais (SCHNALL et al. 2008, p. 12).

A relação do nojo com o aumento da severidade de juízos morais explica por que comportamentos socialmente danosos são apreendidos como fonte de contaminação social. Contudo, não é tão clara a relação de como, por exemplo, a tristeza abranda juízos dentro da esfera da moralidade. Emerge desse ponto a necessidade de um modelo sobre como emoções estimulam desejos e, consequentemente, motivam comportamentos, sem negar ou distorcer os diferentes dados dentro da literatura empírica.

[...] toda emoção parece ter o que pode ser chamado de "marcador de valência". Neste modelo revisado, a tristeza é um estado composto, contendo tanto uma apreciação que detecta a perda, quanto uma ativação que representa a perda como algo negativo (PRINZ, 2004, p. 163).

Há uma considerável literatura empírica sobre os aspectos motivacionais das emoções. Dutton e Aron (1974, p. 516) concluem seu experimento defendendo "[...] a noção de que a emoção forte, em si, aumenta a atração sexual do sujeito para com sua contraparte feminina". A emoção identificada pelos autores foi o medo, que estimulou a atração sexual em condições situacionais ansiogênicas. Por sua vez, Isen e Levin (1972) reportam que a valência emocional positiva é motivacional com relação a comportamentos sociais.

Os resultados dos dois estudos tomados em conjunto fornecem suporte à noção de que se sentir bem leva a ajudar. Porque o sentirse bem tem sido gerado em uma variedade de formas e configurações, e desde que o tipo de medida de ajuda e a fonte das populações estudadas também variaram, essa relação parece ter alguma generalidade empírica (ISEN e LEVIN, 1972, p. 387).

O ponto é que essas pesquisas apenas arranham a superfície da questão, pois cada emoção apresenta como efeito seu próprio perfil motivacional. Por uma questão de clareza argumentativa, esses efeitos serão denominados impulsos genéricos. A escolha deriva do fato de que emoções distintas motivam comportamentos de diversas maneiras, enquanto aquelas pertencentes ao mesmo estado emocional parecem motivar ações de formas semelhantes. Entretanto, não há consenso empírico acerca do funcionamento dos impulsos genéricos. A convergência de resultados é um pouco maior com relação ao fato de que cada emoção fortalece ou enfraquece temporariamente os desejos. A partir desse ponto, pode-se estabelecer que a diferença entre o medo e a raiva é que enquanto o primeiro fortalece desejos direcionados a evitar confrontos, a segunda estimula comportamentos na direção oposta. Todavia, essa distinção abrange todo o escopo dessas emoções, pois a raiva fortalece o desejo de agir agressivamente e o medo 
o faz com relação ao sexo. A hipótese mais plausível é de que alterações de estímulos nos desejos são proporcionais a duração e a intensidade da emoção.

A primeira questão acerca dos impulsos genéricos consiste em explicar como as emoções podem influenciar o comportamento de modos opostos. Por exemplo, o medo pode estimular o desejo de não ser percebido pelo componente dominante de um grupo ao mesmo tempo que pode motivar a aproximação em direção a ele. Frijda (1986, p. 83) argumenta que "a situação meramente provoca a ação; a prontidão da ação existe apenas na medida em que a inibição pode bloquear a execução da ação". À medida que as motivações da ação são fixas e rígidas, a ideia de tendência de comportamento perde muito do seu significado.

Esse problema não surge na concepção de impulsos genéricos. Na medida em que há flexibilidade no modo como emoções influenciam comportamentos, noções como tendência comportamental e prontidão à ação ganham maior peso e significado. No exemplo anterior, em ambos os casos o medo estimula o desejo de evitar o risco. Uma forma natural de evitar o perigo em um grupo em que o componente dominante é um aliado motiva a aproximação, mas quando há incerteza ou, ainda, a certeza de que ele representa um desafeto, não ser percebido é a melhor forma evitar qualquer dano. O ponto em comum entre esses comportamentos é o impulso genérico associado à aversão ao risco.

\begin{abstract}
Programas flexíveis são aqueles que são compostos por cursos alternativos de ação, que permitem a variação de circunstâncias e respostas nas ações executadas. Em tais programas, anseios, intenções e objetivos tornaram-se independentes das ações particulares. [...] Com tal estrutura, é significativo falar da emoção (FRIJDA, 1986, p. 83).
\end{abstract}

A segunda questão acerca dos impulsos genéricos está na possibilidade de resistir a eles. Da ideia de que um desejo é estimulado pela intensidade emocional não decorre que ele sempre conduzirá a um comportamento específico e descontrolado; o que é um traço de grande valor adaptativo. Por exemplo, a resistência ao nojo permite que se limpe um bebê, e o autocontrole da raiva pode evitar um confronto letal. O ponto é que resistir a um impulso genérico não significa que ele não seja sentido. O autocontrole em um episódio de raiva pode evitar o confronto físico, entretanto, pode se manifestar em tremores musculares, de modo que sua repressão também possa gerar fadiga física e emocional. O importante aqui é que a heteronomia das respostas comportamentais e a ausência ocasional de expressão das emoções são compatíveis com a ideia de impulso genérico.

A pergunta central aqui é se a visão perceptiva possui a mesma compatibilidade. Enquanto concebidas como percepções corporificadas, as emoções podem influenciar o comportamento de duas formas, pelo seu conteúdo ou sua valência. Prinz (2004, p. 174) salienta que "[...] marcadores de valência podem impactar tanto o comportamento presente quanto o futuro. Eles influenciam o futuro em virtude da sua habilidade de influenciar o presente". $O$ ponto é que a valência emocional não estimula a continuidade ou encerramento 
dos temas relacionais nucleares, conforme é defendido pelo autor. A crítica é que a visão perceptiva não consegue, amparada em fatores de valência, explicar o porquê da raiva (valência negativa) motivar tanto o encerramento de uma discussão ofensiva quanto a inclinação para entrar em um confronto; da mesma forma que o medo (valência negativa) motiva tanto a fuga do perigo quanto estimula a atração sexual.

Para avançar nessa questão, é insuficiente estabelecer que percepções corporais representam emoções em vez de temas relacionais nucleares. Em geral, percepções são acompanhadas de atitudes mentais assertivas, cuja função está em afirmar mentalmente algo. Uma vez que impulsos genéricos alteram a intensidade dos desejos, é necessário explicar por que afirmar mentalmente um estado emocional sistematicamente induz uma predisposição a determinados comportamentos.

\subsection{EMOÇÕES E OS ESTADOS PERIFÉRICOS}

Após analisar os problemas enfrentados pela visão perceptiva, é intelectualmente honesto realizar o mesmo com a visão periférica. Embora a Premissa de Lange não seja alvo das mesmas objeções, o argumento é que ela é igualmente insuficiente para responder às questões levantadas neste artigo. Serão realizadas duas objeções principais a essa visão, com ambas as críticas direcionadas à defesa de que percepções corporais mediam a relação entre os estados periféricos e centrais. ${ }^{8}$

A visão periférica parte da premissa de que estados periféricos engatilham percepções corporais que produzem as características comportamentais e motivacionais qualitativas das emoções. James (1922, p. 65) defende que a emoção "não pode existir, contudo, sem seus atributos físicos". Em suma, a Premissa de Lange identifica as emoções com os estados periféricos, com sua força motivacional sendo mediada por percepções corporais. O argumento é que a manipulação direta da percepção corporal produz os mesmos impulsos genéricos suscitados pelos estados periféricos. Uma vez que ela produza efeitos emocionais específicos, parece inegável que estes sejam considerados como emoções genuínas.

De fato, não é difícil provar agora, e por meio das experiências mais comuns e ordinárias, que as emoções podem ser induzidas por uma variedade de causas que são totalmente independentes das perturbações da mente, e que, por outro lado, elas podem ser suprimidas puramente por meios físicos (LANGE, 1922, p. 66).

A Premissa de Lange estabelece que, ao manipular as percepções corporais para induzir uma emoção que ocorre em certo contexto situacional, também se estará estimulando o estado periférico que constitui determinada emoção. Uma vez que esse estado periférico não seja real, a visão periférica caracteriza essa reação

\footnotetext{
${ }^{8} \mathrm{O}$ objetivo desta classificação é destacar o contraste entre os estados cerebrais. Nesse sentido, estados centrais são governados pelo sistema nervoso central, enquanto os estados periféricos são regidos pelo sistema nervoso periférico.
} 
como alucinatória. Lange (1922, p. 71) esclarece que "o frenesi causado por um cogumelo, por exemplo, ou por mania, pode ter a mesma aparência de raiva, mas não é a verdadeira raiva, tão pouco como a alegria que vem de beber vinho não é alegria real [...]". A crítica é que em todos os casos mencionados os impulsos genéricos são idênticos. Desse modo, os defensores da visão periférica precisam explicar por que a manipulação de percepções corporais não produzem emoções genuínas.

Conforme colocado no início desta seção, a segunda objeção também é baseada na concepção da visão periférica de que percepções corporais mediam os efeitos dos estados periféricos. Lange (1922, p. 80 - tradução do autor) ressalta que "se as impressões que recaem sobre os nossos sentidos não possuíssem o poder de estimulá-los, nós vagaríamos pela vida sem simpatia e paixão [...]”. A crítica consiste no fato de que caso as percepções corporais engatilhem os impulsos genéricos mediante um erro na transmissão da informação, então os estados periféricos não poderiam desempenhar melhor essa função, pois seus efeitos são mediados por essas percepções. Nesse quesito, a crítica apresentada anteriormente à visão perceptiva também se aplica à visão periférica.

\begin{abstract}
Caso a concepção da natureza dos afetos aqui representados seja estabelecida, então podemos esperar que toda influência envolvendo mudanças gerais no sistema nervoso vascular deve ter uma expressão emocional. Evidentemente, não podemos esperar que essas emoções coincidam exatamente com o fenômeno para o qual, geralmente, nós reservamos essa denotação; as diferenças na causa resultarão naturalmente em vários efeitos (LANGE, 1922, p. 68 - tradução do autor).
\end{abstract}

Na seção anterior, argumentou-se que a valência emocional de percepções corporais não produz impulsos genéricos. No momento em que a visão periférica coloca a percepção corporal como mediadora da emoção, a valência apenas influencia o desejo de modo que esta seja prolongada ou encerrada. O argumento é que a consciência da emoção possibilita a preferência pela sua permanência ou não, sendo que isso a diferencia de estados alucinógenos ou patológicos, pois apenas no primeiro caso ela denota corretamente a relação com o fenômeno real. A crítica é que essa distinção não explica por que emoções produzem impulsos genéricos.

Na Premissa de Lange, caso os estados periféricos produzam impulsos genéricos, estes seriam mediados por estados centrais a partir do conteúdo informacional recebido mediante percepções corporais. Lange (1922, p. 79) é categórico ao afirmar que "as emoções não são forças que estão fora do corpo [...]". Nesse caso, o problema está na possibilidade de os estados periféricos não influenciarem os desejos. Na visão periférica, as melhores candidatas para desempenhar essa função são as percepções corporais. No entanto, uma vez que elas não produzem impulsos genéricos, então não há um mediador adequado aos estados periféricos e, consequentemente, eles também não podem desempenhar essa função. 
Em linhas gerais, há duas formas de resolver essa questão. Na primeira possibilidade é possível argumentar que o estímulo periférico é mediado por outro tipo de estado que, oposto à percepção corporal, é adequado para produzir impulsos genéricos. Esse argumento necessita de três etapas centrais. A primeira consiste na distinção entre percepções corporais e estados centrais não perceptuais, que receberiam os estímulos periféricos. A segunda se refere a uma possível existência de estados centrais não perceptuais, que receberiam os estímulos dos estados periféricos relevantes. A terceira está direcionada a necessidade de esses estados serem mais adequados do que as percepções corporais para produzir os impulsos genéricos.

As duas primeiras etapas não são controversas, enquanto a terceira apresenta o problema central. Na possibilidade apresentada, os estados centrais só seriam diferentes das percepções corporais se representassem estados periféricos. O ponto é que, considerando que eles recebem estímulos exatamente desses estados, não fica claro qual seria sua outra função. É possível argumentar que os estados periféricos possuem o perfil psicossemântico que a visão perceptiva atribui às percepções corporais, de modo que eles representassem temas relacionais nucleares. Todavia, isso levanta novos problemas. O primeiro é que não há evidências empíricas que corroborem essa hipótese. Já o segundo, conforme fora argumentado anteriormente, consiste no fato de que um estado qualquer que represente um tema relacional nuclear não é adequado para produzir impulsos genéricos. Em uma perspectiva evolutiva, pode-se acrescentar ainda que isso não proporciona qualquer vantagem adaptativa ou economia energética.

A segunda possibilidade para resolver essa questão seria argumentar que as percepções corporais são facilitadoras dos impulsos genéricos. Além de ser contrário à primeira possibilidade, esse argumento é triangular. Nesse caso, a defesa da visão periférica necessita que percepções corporais possam facilitar a produção de impulsos genéricos. O ponto é que essa possibilidade enfraquece a primeira crítica contra a visão perceptiva desenvolvida anteriormente. A menos que as percepções corporais possam ser facilitadoras dos impulsos genéricos, tanto a visão perceptiva quanto a visão periférica possuem problemas. Por outro lado, caso fosse possível (o que não tem nenhum respaldo empírico), então os argumentos das seções anteriores favoreceriam a Premissa de James com relação à Premissa de Lange que, de qualquer forma, fica enfraquecida.

\section{ESTADOS EMOCIONAIS E A VISÃO SISTÊMICA}

A visão periférica fica enfraquecida quando confrontada com abordagens corporificadas mais atuais das emoções. O argumento principal apresentado na parte final deste artigo é que uma visão sistêmica sobre as emoções não possui as mesmas vulnerabilidades. O ponto de partida é o mesmo da Premissa de Lange, que coloca os estados periféricos como parte das emoções, com a diferença de que também se inclui os estados centrais como necessários à sua existência. Considera-se essa abordagem sistêmica precisamente por colocar os sistemas nervosos central e periférico como fundamentais aos estados emocionais. 
Estabelecer a relação entre os sistemas nervosos central e periférico, assim como suas respectivas funcionalidades, é fundamental para esclarecer a visão sistêmica. Os componentes periféricos têm duas funções principais: preparar o corpo para realizar determinadas ações e sinalizar estados emocionais. Os componentes centrais têm a função primária de produzir impulsos genéricos e demais efeitos psicológicos. Ordinariamente, ambos atuam em unidade para manter a funcionalidade do organismo. Por exemplo, quando o sistema nervoso periférico reage agressivamente e sinaliza pela expressão corporal a prontidão para ações de confronto, essa informação é transmitida ao sistema nervoso central, que produz um impulso genérico que estimula esse comportamento. Da mesma forma, quando o sistema nervoso central produz um impulso genérico que estimula a agressividade, essa informação é transmitida ao sistema nervoso periférico, que prepara o corpo para a ação, sinalizando-o pela expressão corporal.

Mesmo entre posições cognitivistas, não é controverso que estados periféricos sejam os responsáveis pela expressão corporificada de emoções. A controvérsia está na premissa de que alterações periféricas sejam estímulos motivacionais, uma vez que essa função seria exclusiva do sistema nervoso central. O problema ocorre quando é colocado que um estímulo motivacional necessita de uma reação corporal correspondente, pois as emoções são essenciais na comunicação interpessoal e isso requer a existência de sinalizadores externos. Griffiths e Scarantino (2009, p. 5) colocam que "emoções têm sido vistas como respostas mais ou menos precisas sobre como as coisas são, mas elas também são e, talvez principalmente, mais ou menos respostas eficazes orientadas para objetivos". A flexibilidade oferecida por essa abordagem coloca no nível biológico a contribuição das emoções com relação à aptidão social e à funcionalidade do grupo, enquanto elementos externos, como a cultura, estabelecem gatilhos que não existiam no contexto natural. Nesse caso, a relação é possível apenas porque existe uma estrutura biológica apta a receber as influências do ambiente, sendo flexível o suficiente para moldar e ser moldada por ele.

Em contraste, uma perspectiva situada sobre a emoção enfatiza o papel do contexto social na produção e no gerenciamento de uma emoção, e a influência recíproca da emoção no contexto social em evolução. Comportamentos que tradicionalmente têm sido vistos como expressões involuntárias do estado psicológico do organismo são vistos como sinais projetados para influenciar o comportamento de outros organismos ou como "movimentos" estratégicos em uma transação contínua entre organismos (GRIFFITHS e SCARANTINO, 2009, p. 4).

O componente social das emoções tem um aspecto estratégico negligenciado nas abordagens cognitivistas dentro do escopo teórico desenvolvido por James-Lange. Já a visão sistêmica defende essa funcionalidade mediante uma relação entre os sistemas nervosos central e periférico, que é estabelecida por reforços mútuos. Morris e Keltner (2000, p. 20) reforçam que "[...] emoções podem ser vistas como tendo funções - não porque foram projetadas, mas porque foram selecionadas com base em sua adaptabilidade [...]". Defende-se aqui a utilidade de expressar intenções quando se está genuinamente motivado a realizar determinada 
ação e há condições físicas para isso. O perigo está em expressar a intencionalidade sem que exista motivação ou capacidade para se comportar adequadamente. Por esse motivo é fundamental que exista sincronia entre a motivação e a modulação das reações corporais.

Empiricamente, a sugestão de dividirmos a operação do programa dos afetos da "emoção cognitiva superior" parece ignorar [...] a extensão em que a tomada de decisões de "ordem superior" tem que se valer do sistema límbico para funcionar (BLACKBURN, 1998, p. 129).

A exigência de uma integração sistêmica efetiva para o funcionamento de organismos complexos não é algo estranho à literatura empírica em biologia. Afinal, todos os mamíferos superiores possuem essas características bem documentadas. A questão não é que exista relação entre os sistemas nervosos central e periférico, mas que estes estejam identificados com as emoções. Justificase a defesa da visão sistêmica pela sua capacidade de resolver de maneira mais simples os problemas levantados nas discussões atuais acerca tanto da visão perceptiva quanto da visão periférica.

\subsection{COMPONENTES CENIRAIS DA VISÃO SISTÊMICA}

O ponto principal desta seção é identificar os componentes centrais da visão sistêmica a partir da sua capacidade de produzir impulsos genéricos. Sustenta-se que esses componentes estão associados a um módulo cerebral central vinculado ao sistema nervoso central, responsável pela produção de impulsos dessa natureza. O objetivo central será definir os módulos cerebrais envolvidos nesse processo de forma mais precisa. O caminho a ser trilhado é o de estabelecer maior comprometimento com as questões balizadoras do debate contemporâneo sobre os estados emocionais.

Os componentes centrais da visão sistêmica são identificados como estados emocionais. Eles produzem estímulos motivacionais inerentemente emocionais, com a particularidade de fazê-los de forma difusa. Esse ponto é problemático em relação às teorias que colocam a intencionalidade a um objeto como necessária aos estados emocionais. Crane (1998, p. 234) defende que "as dores normalmente parecem ter localização e extensão no espaço e tempo, e nós falamos delas sem esforço usando termos singulares e predicamos propriedades delas como fazemos a objetos e eventos". A ideia é que as emoções se direcionam a objetos específicos, ainda que não se tenha consciência deles. Solomon (1976) apresenta uma resposta, defendendo que estados emocionais estão identificados com objetos de alcance geral.

Uma emoção não é distinta ou separável de seu objeto; o objeto como um objeto desta emoção não tem existência separado da emoção. Há dois componentes, minha raiva e o objeto da minha raiva [...] toda emoção tem a forma unitária de "minha-emoção sobre...", "estou com raiva de..." [...] A emoção é distinguida pelo seu objeto; não há nada além do seu objeto. Mas também não há tal objeto sem a emoção (SOLOMON, 1976, p. 178). 
Essa abordagem coloca os componentes centrais dos estados emocionais como uma classe especial de desejo ou aversão, pois seriam constituídos por atitudes mentais do mesmo tipo. A emoção do medo passa a ser uma aversão a um mal generalizado, da mesma forma que a tristeza seria com relação à perda. Por exemplo, a visualização de uma aranha engatilha uma aversão expressa pelo medo de ser atacado, produzindo também uma aversão generalizada ao risco de sofrer danos físicos e engatilhando um processo que resulta em um estado periférico específico. Da mesma forma, outras aversões ou desejos são capazes de engatilhar processos que produzirão novos estados periféricos que serão influenciados por inúmeros fatores externos.

O problema é que essa abordagem não explica a característica episódica das emoções e, consequentemente, os efeitos da manipulação periférica. É um ponto pacífico estabelecer que nojo e raiva podem coexistir, mas o mesmo não se aplica à alegria. O nojo ou a alegria podem sobrepujar um ao outro, mas nenhum será inteiramente dominante em estados emocionais compostos por emoções opostas. A coexistência harmônica entre a raiva e o nojo ocorre porque ambos estão no mesmo escopo de valência. Isso não se deve a intencionalidade ou relação com um objeto específico, mas simplesmente a constituição biológica de ambos. Dessa forma, no nojo provocado por manipulação periférica, o impulso genérico é compatível ao manifestado pela raiva, e ambos são opostos ao encontrado na alegria. Essa oposição ocorre porque o cérebro de mamíferos superiores não comporta permanentemente a simultaneidade dos estados emocionais associados a emoções de valência oposta, desencadeando um colapso nervoso caso uma não sobrepuje a outra.

É verdade que a maioria das pessoas não se torna emocional para cumprir alguma obrigação social. Mas, uma análise dos papéis não é mais objetável a este respeito do que uma análise em termos de padrões adaptativos baseados na biologia [...] qualquer episódio específico de raiva, amor, ... etc. pode não atender a nenhuma necessidade social. Mas, caso em média ou a longo prazo tais síndromes emocionais estiverem em conformidade com as normas sociais, então seu resultado líquido será funcional dentro do sistema social (AVERILL, 1980, p. 336).

A intencionalidade não é necessária para compreender a funcionalidade dos estados emocionais. Griffiths (1997, p. 148) coloca que "a resposta emocional é produzida 'estrategicamente' com a intenção de extrair uma resposta adequada dos outros. Mas a resposta emocional é interpretada pelo agente e sua comunidade como natural e involuntária”. Nessa linha, Sizer (2000) também argumenta que os componentes centrais das emoções não possuem conteúdo intencional.

Mudanças nas operações neste nível (funcional) têm efeitos globais nos estados e processos do nível de representação, mas de uma forma que é independente do conteúdo semântico destes estados. As mudanças são de baixo para cima e, portanto, influenciam a criação e o desempenho de todas as representações e processos representacionais afetados. Isto é o que explica os efeitos 
generalizados e independentes de conteúdo do humor (SIZER, 2000, p. 763).

A visão sistêmica relaciona não apenas os estados emocionais com aspectos funcionais, mas também o faz com relação a seus componentes centrais. As emoções engatilham impulsos genéricos e alteram temporariamente os parâmetros na ordem dos desejos e aversões. A questão vantajosa dessa abordagem é que ela explica com maior simplicidade a abrangência dos estados emocionais. Isso ocorre porque seus componentes centrais não constituem uma mera representação dentro de um sistema, mas um estado corporificado que modela as representações dentro dele. Dessa forma, é possível que emoções contrárias apresentem, enquanto componentes parciais dos estados emocionais, efeitos diacrônicos dentro de um mesmo organismo.

\section{CONCLUSÃO}

Em grande parte, a estrutura geral da visão sistêmica se apoia na unificação dos temas centrais à discussão com aqueles que se encontram relegados a um segundo plano. O presente artigo apresentou uma questão central à visão sistêmica e ao modo como emoções podem ser compreendidas, ou seja, que a manipulação periférica altera as emoções. Esse ponto não é especificamente controverso, mas é considerado por muitas abordagens como um fenômeno marginal. As mudanças periféricas alteram as motivações pelo mesmo motivo que as alterações motivacionais modificam os estados periféricos, pois os sistemas responsáveis pela motivação, preparação da ação e expressão estão integrados. Em suma, as emoções são os estados que resultam da integração entre esses sistemas.

Dado o exposto, conclui-se que há suporte na literatura empírica à ideia de que a manipulação periférica influencia as emoções, de modo que apresenta consequências emocionais genuínas. Grande parte dos pesquisadores interessados no estudo das emoções utiliza esse ponto para defender a tradição James-Lange contra diversas teorias contemporâneas sobre o tema. Buscou-se apresentar que esse fundamento também pode ser utilizado para criticar posições dentro desse escopo teórico. É fato que há um longo caminho para se desenvolver de maneira mais completa os componentes centrais que integram os estados emocionais. Em suma, o objetivo deste artigo foi realizar um estudo exploratório inicial acerca dessa possibilidade, de modo a indicar que não há impeditivos óbvios para o desenvolvimento integral de uma visão sistêmica.

\section{REFERÊNCIAS}

ADOLPHS, Ralph et al. A role for somatosensory cortices in the visual recognition of emotion as revealed by three-dimensional lesion mapping. The Journal of Neuroscience, v. 20, n. 7, p. 2685-2690, 2000. 
AVERILL, James R. A constructivist view of emotion. In: PLUTCHIK, Robert e KELLERMAN, Henry (eds.). Theories of emotion. New York, NY: Academic, 1980. p. 305-339.

BECHARA, Antoine et al. Insensitivity to future consequences following damage to human prefrontal cortex. Cognition, v. 50, p. 7-15, 1994.

BERNTSON, Gary G. et al. The insula and evaluative processes. Psychological Sciences, v. 22, n. 1, p. 80-86, 2011.

BLACKBURN, Simon. Ruling Passions: A theory of practical reasoning. New York, NY: Oxford University Press, 1998.

BURGE, Tyler. Individualism and psychology. Philosophical Review, v. 95, p. 3-45, 1986.

CACIOPPO, John T., et al. The psychophysiology of emotion. In: LEWIS, Michael e HAVILAND, Jeannette M. (ed.). Handbook of Emotions. New York: Guilford Press, 2000. p. 173-191.

CANNON, Walter B. The James-Lange theory of emotion: A critical examination. American Journal of Psychology, v. 39, p. 106-124, 1927.

CHWALISZ, Kathleen, DIENER, Ed, e GALLAGHER, Dennis. Autonomic arousal feedback and emotional experience: Evidence from the spinal cord injured. Journal of Personality and Social Psychology, v. 54, p. 820-828, 1988.

CRAIG, A. D. How do you feel - now? The anterior insula and human awareness. Nature Reviews Neuroscience, v. 10, p. 59-70, 2009.

CRANE, Tim. Intentionality as the mark of the mental. In: O'HEAR, Anthony (ed.). Contemporary Issues in the Philosophy of Mind. Cambridge: Cambridge University Press, 1998. p. 229-251.

DAMÁSIO, Antonio R. Descartes' Error: Emotion, reason, and the human brain. New York: Grosset/Putnam, 1994.

The feeling of what happens: Body and emotion in the making of consciousness. New York: Harcourt Brace \& Company, 1999.

DARWIN, Charles R. The expression of the emotions in man and animals. London, RU: John Murray, 1872.

DRETSKE, Fred. Explaining Behavior: Reasons in a World of Causes. Cambridge, MA: MIT Press, 1988.

DUTTON, Donald G. e ARON, Arthur. Some evidence for heightened sexual attraction under conditions of high anxiety. Journal of Personality and Social Psychology, v. 30, n. 4, p. 510-517, 1974.

EKMAN, Paul e FRIESEN, Wallace. V. Constants across cultures in the face and emotion. Journal of Personality and Social Psychology, v. 17, p. 124-129, 1971.

et al. Autonomic nervous system activity distinguishes among emotions.

Science, v. 221, p. 1208-1210, 1983. 
ELLSWORTH, Phoebe C. e SCHERER, Klaus. R. Appraisal processes in emotion. In: DAVIDSON, Richard J., SCHERER, Klaus. R. e GOLDSMITH, H. Hill (ed.). Handbook of Affective Sciences. New York, NY: Oxford University Press, 2003. p. 572-595.

FOLKOW, B Björn. Perspectives on the integrative functions of the 'sympthoadrenomedullary system'. Autonomic Neuroscience: Basic and Clinical, v. 83, p. 101-115, 2000.

FRIJDA, Nico. The emotions. New York: Cambridge University Press, 1986.

GRIFFITHS, Paul. E. What emotions really are. Chicago, IL: University of Chicago Press, 1997.

e SCARANTINO, Andrea. Emotions in the wild: The situated perspective on emotion. In: ROBBINS, Philip e AYDEDE, Murat (eds.). Cambridge handbook of situated cognition. New York, NY: Cambridge University Press, 2009. p. 437-453.

HEIMS, H. C. et al. Social and motivation functioning is not critically dependent on feedback of autonomic responses: neuropsychological evidence from patients with pure autonomic failure. Neuropsychologia, v. 42, n. 14, p. 1979-1988, 2004.

HOHMANN, George. W. Some effects of spinal cord lesions on experienced emotional feelings. Psychophysiology, v. 3, p. 143-156, 1966.

ISEN, Alice M. e LEVIN, Paula. F. Effect of feeling good on helping: cookies and kindness. Journal of Personality and Social Psychology, v. 21, n. 3, p. 384-388, 1972.

JAMES, William. What is an emotion? In: DUNLAP, Knight (ed.). The emotions. Baltimore: Waverly Press, 1922. p. 11-30.

KREIBIG, Sylvia D. Autonomic nervous system activity in emotion: A review. Biological Psychology, v. 84, n. 3, p. 394-422, 2010.

LANGE, Carl G. The emotions. In: DUNLAP, Knight (ed.). The emotions. Baltimore: Waverly Press, 1922. p. 33-90.

LAZARUS, Richard S. Emotion and adaptation. New York, NY: Oxford University Press, 1991.

LERNER, Jennifer S. e KELTNER, Dacher. Fear, anger, and risk. Journal of Personality and Social Psychology, v. 81, p. 146-159, 2001.

MILlIKAN, Ruth G. White Queen psychology and other essays for Alice. Cambridge: MIT Press, 1993.

MORRIS, Michael W. e KELTNER, Dacher. How emotions work: The social functions of emotional expression in negotiations. Research in Organizational Behavior, v. 22, p. 1-50, 2000.

NUSSBAUM, Martha C. Upheavals of thought: The intelligence of the emotions, Cambridge, RU: Cambridge University Press, 2001.

PHILIPPOT, Pierre, CHAPELLE, Gaëtane, e BLAIRY, Sylvie. Respiratory feedback in the generation of emotion. Cognition \& Emotion, v. 16, n. 5, p. 605-627, 2002. 
PRINZ, Jesse J. Furnishing the mind: Concepts and their perceptual basis. Cambridge, Massachusetts: MIT Press, 2002.

Gut reactions. New York, NY: Oxford University Press. 2004.

RUSSELL, James. A. Is there universal recognition of emotion from facial expression? A review of cross-cultural studies. Psychological Bulletin, v. 115, p. 102-141, 1994.

SCHNALL, Simone et al. Disgust as embodied moral judgment. Personality and Social Psychology Bulletin, v. 34, n. 8, p. 1096-1109, 2008.

SEQUEIRA, Henrique et al. Electrical autonomic correlates of emotion. International Journal of Psychophysiology, v. 71, n. 1, p. 50-56, 2009.

SIZER, Laura. Towards a computational theory of mood. British Journal of the Philosophy of Science, v. 51, p. 743-769, 2000.

SMITH, Craig A. e KIRBY, Leslie. D. Core relational themes. In: SANDERS, David e SCHERER, Klaus R. (eds.). The Oxford Companion to Emotion and the Affective Sciences. New York, NY: Oxford University Press, 2009. p. 104-105.

e LAZARUS, Richard. S. Emotion and adaptation. In: PERVIN, Lawrence A. (ed.). Handbook of personality: Theory and research. New York, NY: The Guilford Press, 1990. p. 609-637.

SOLOMON, Robert C. The passions. New York, NY: Doubleday. 1976.

. On emotions as judgments. American Philosophical Quarterly, v. 25, n. 2, p. 183-191. 1988.

SOUSSIGNAN, Robert. Duchenne smile, emotional experience, and autonomic reactivity: A test of the facial feedback hypothesis. Emotion, v. 2, n. 1, p. 52-74, 2002.

STEPPER, Sabine e STRACK, Fritz. Proprioceptive determinants of affective and nonaffective feelings. Journal of Personality and Social Psychology, v. 64, n. 2, p. 211-220, 1993.

STORBECK Justin e WYLIE Jordan. The functional and dysfunctional aspects of happiness: Cognitive, physiological, behavioral, and health considerations. In: LENCH, Heather (ed.). The Function of Emotions. Springer, 2018. p. 195-220.

STRACK, Fritz, MARTIN, Leonard L. e STEPPER, Sabine. Inhibiting and facilitating conditions of the human smile: A nonobtrusive test of the facial feedback hypothesis. Journal of Personality and Social Psychology, v. 54, n. 5, p. 768-777, 1988.

Recebido em: 06-03-2019

Aceito para publicação em: 02-07-19 